九州大学学術情報リポジトリ

Kyushu University Institutional Repository

\title{
Control rule acquisition for an arm wrestling robot
}

Kamohara, Shinichi

Nagasaki Institute of Applied Science

高木，英行

Kyushu Institute of Design

Takeda, Takashi

Nagasaki Institute of Applied Science

http://hdl. hand le. net/2324/4486267

出版情報 : 1997 IEEE International Conference on Systems, Man, and Cybernetics. 5, pp.42274231，1997-10-12. IEEE バージョン :

権利関係 : 


\title{
Control Rule Acquisition for an Arm Wrestling Robot
}

\author{
Shinichi Kamohara ${ }^{\star}$, Hideyuki Takagi“», Takashi Takeda* \\ * Nagasaki Institute of Applied Science \\ 536, Aba, Nagasaki, 851-01, JAPAN \\ **Kyushu Institute of Design \\ 4-9-1, Shiobaru, Minami-ku, Fukuoka, 815 JAPAN \\ kamo@cc.nias.ac.jp, takagi@artemis.kyushu-id.ac.jp, takeda@csce.nias.ac.jp
}

\begin{abstract}
This paper describes knowledge acquisition for an arm wrestling virtual reality (VR) system. The ultimate goal of this research is to obtain control rules which give the impression that the operator is arm wrestling against a real person and to analyze what factors enhance this.

Control rules are obtained in two stages, because it is difficult to directly obtain rules for VR. Firstly the rules necessary to win, arm wrestling games are obtained, and then they are modified into the ones which enhance VR. This paper focuses on the former stage. Acquiring the rules to win games consists of two steps.

We are evaluating if the obtained fuzzy rules are equivalent to the original 20,000 precise rules through subjective test.
\end{abstract}

\section{INTRODUCTION}

In recent years, research in the field of virtual reality (VR) has been increasing. Significant research has also been carried out in the more fundamental fields looking at the psychological and physiological aspects of virtual reality as well as the realization and application of VR [1].

The goal of this research is to analyze some primary factors that together give the sense of virtual reality. The analysis looks specifically at which VR senses, that is which primary factors by their addition to the VR control system would enhance the sense of virtual reality. In this paper, the creation of an artificial imaginary arm-wrestling opponent was taken up as the subject on which this study was based. The first milestone was the construction of an experimental physical armwrestling opponent system and a control system capable of automatically and dynamically acquiring control rules. In armwrestling the main aspect is the exchange of power. In this case via the arm, however the provision of an appropriate imaginary environment and an imaginary opponent is also necessary. This second part of the VR system has now also been constructed.

Section 2 describes the construction of the equipment providing the VR environment [2]. The physical arm-wrestling system itself is constructed using pneumatically activated drivers which together with its control system simulates an opponent to a human operator. Section 3 describes the acquisition of armwrestling control rules on the basis of the classifier system (CS) [3][4]. Under this system, 20,000 control rules are dynamically acquired during the arm-wrestling bouts. From this information, it is possible to calculate the comparative efforts exerted by different human operators. However, in arm-wrestling, it is not possible to obtain the Input-Output characteristic from the arm of the human operator. Consequently, we construct appraisal rules which are in effect a set of rules defining 
"how to win over the opponent". In Section 4, we compile these control rules into 8 fuzzy control rules using parameters referred to as the FS (fuzzy system) and GA (genetic algorithm) parameters, as it is difficult to make an analysis of VR sensory primary factors from 20,000 classifier rules. Furthermore in terms of programming using fuzzy control rules, it is possible to create a specific information base on which an analysis of the various VR senses can be made.

\section{CONSTRUCTION OF THE EQUIPMENT PROVIDING THE VR ENVIRONMENT}

Figure 1 shows the arm-wrestling system equipment [2]. The operator puts on a Head Mounted Display(HMD) and fits an othosis on their arm. The othosis provides the mechanism for force communication. Sound effects are also provided. The HMD has a noncontact position sensor(gyroscopic type) onboard in order to measure head movement. This directional information is input to a workstation(WS). Upon processiong this outputs display information appropriate to the direction to which the operator is facing, thus providing the visual-spacial sensory aspect essential in a VR system.

This system can be divided into three parts as shown in Figure 1. The first part is the visual display sub-system providing the visual aspect of the virtual world. Its main parts are a workstation, a 3-D graphics board, an NTSC convertor, and the HMD. The second part is an auditory sub-system used to generate various sound effects based on that which occurs within the virtual world. Direction is also accounted for further enhancing the spatial sense. This sub-system consists of a MIDI interface, sampler, effects unit, amplifier, and speakers. The third part is the force generatingevaluation sub-system providing control of the pneumatically activated drivers. This consists of a $\mathrm{PC}$, a D/A convertor, a VC (voltagecurrent) conversion device, and an electromagnetic proportional valve.

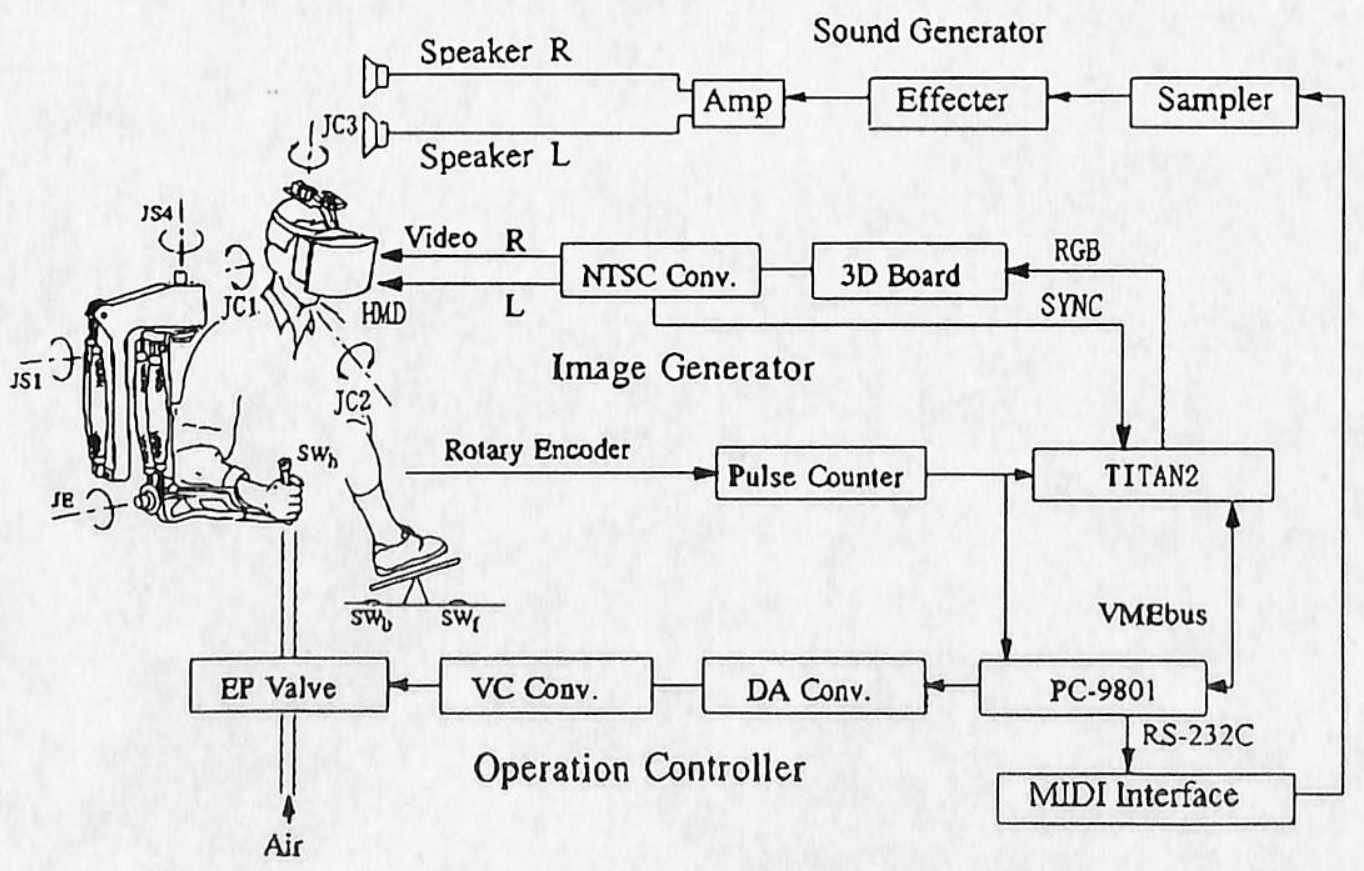

Fig 1. VR system 
During the arm-wrestling bout, joint angle information obtained from a rotary encoder on the othosis is input to both the WS and the PC. The HMD graphics are thus updated based on this angle to provide an appropriate image of the upper part of the virtual opponent including the opponents arm. While the PC uses the angular information to output an appropriate 12 bit code to alter the control information to the pneumatic rubber actuator (RUB). The 12 bit code is firstly converted by the D/A convertor to a voltage then via the $\mathrm{VC}$ convertor into a current. This current fed to the electromagnetic proportional valve alters the pneumatically activated drivers air pressure and thus alters the force that it exerts upon the operator.

\section{ACQUISITION OF ARM-WRESTLING RULES}

The first step necessary in the acquisition of arm-wrestling rules is to define a system in which the rules can be classified. The CS thus represents this series of rules. The CS is divided into a condition part and an action part they representing the arm-wrestling bouts current status as obtained from the othosis's rotary encoder and the output code to the force actuator respectively [4].

In defining the arm-wrestling bouts status for the condition part of the classifier the following three attributes are taken into account based on the information obtained from the othosis's rotary encoder .

(1) Angular position of the arm (12 bits)

(2) Angular speed of the arm (7 bits)

(3) Angular acceleration of the arm (7 bits)

(4) Force (control information to the RUB) (6bits)

The othosis's rotary encoder only provides angular information, however by sampling this output at fixed intervals both angular speed and acceleration are calculated. This information is then binary coded for the condition part of the classifier. The condition part is made up of a total of 26 bits, angular position 12 bits, angular speed 7 bits and angular acceleration 7 bits. The action part of the classifier stores the code that controls the othosis's output force. A six-bit code is used to represent the othosis's control status. The initial classifier bit string consisting of the condition part 26 bits and the action parts 6 bits thus in total 32 bits are generated randomly.

The virtual opponent learns how to win the arm-wrestling bout based on these classifiers, thus as the game progresses the virtual opponent becomes more capable increasingly. This relationship is shown in Figure 2. A maximum of 20,000 classifiers has been set. The target being to in effect out-push the opponent. Consequently, it is essential that the CS bases it's evaluation of CS rules on the degree to which the angle was able to be advanced, this angle being derived from the action part of the classifier.

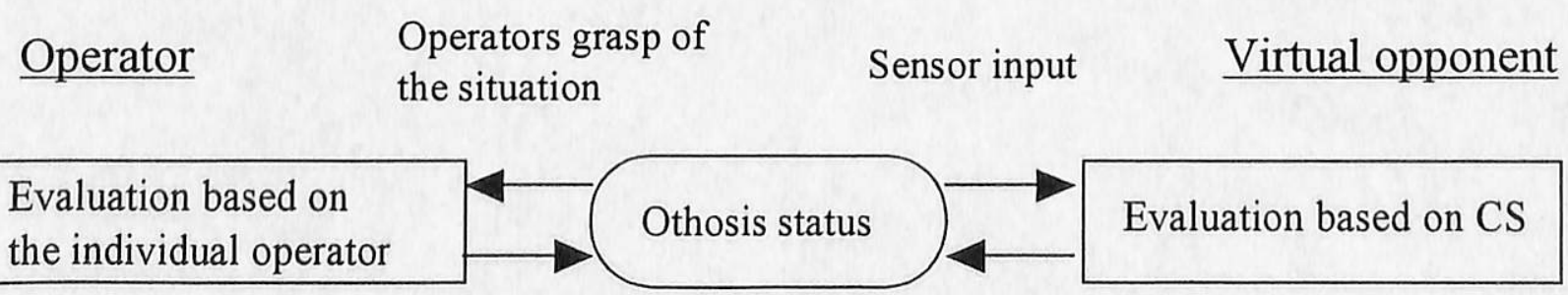

Operator effort

Code output to drivers

Fig. 2. Arm wrestling status (Operator vs. Virtual opponent) 
The CS control rules to win are obtained based on the criteria of pushing the opponent, when the opponent pushes down the arm of the operator that particular CS control rule's value is raised.

\section{COMPILATION OF CS RULES INTO FUZZY RULES}

This section explains how the 20,000 CS rules obtained in section 3 are translated into a small number of fuzzy rules. The rules obtained by the CS are approximated by the fuzzy rules which are referred to as 'membership functions'. GA is used for optimization purposes in this respect. The fuzzy model forms a triangular membership function. It is by reference to this model that an output value (action part of the CS) is obtained. Each GA code is thus assigned one of a maximum of 8 values thus a maximum of 8 fuzzy rules. Consequently in three dimensions this gives a maximum of $8^{3}=512$ fuzzy rules. However, due to normalization the actual number of rules is less than this. A smaller number of rules leads to a more optimal system, however, will always be offset by some penalty. The detail of this GA coding is based on the reference [5].

An example of this obtaining fuzzy rules is shown in Figure 3. As it is difficult to display this division in 3 dimensions line segments have been used to mark out the target value. The values within the diagram represent output values of the virtual opponent. A small angle represents the operator being in an advantageous position while a large angle the virtual opponent being in an advantageous position. A positive velocity indicates the virtual opponent making progress if negative one indicates the operator is making progress.

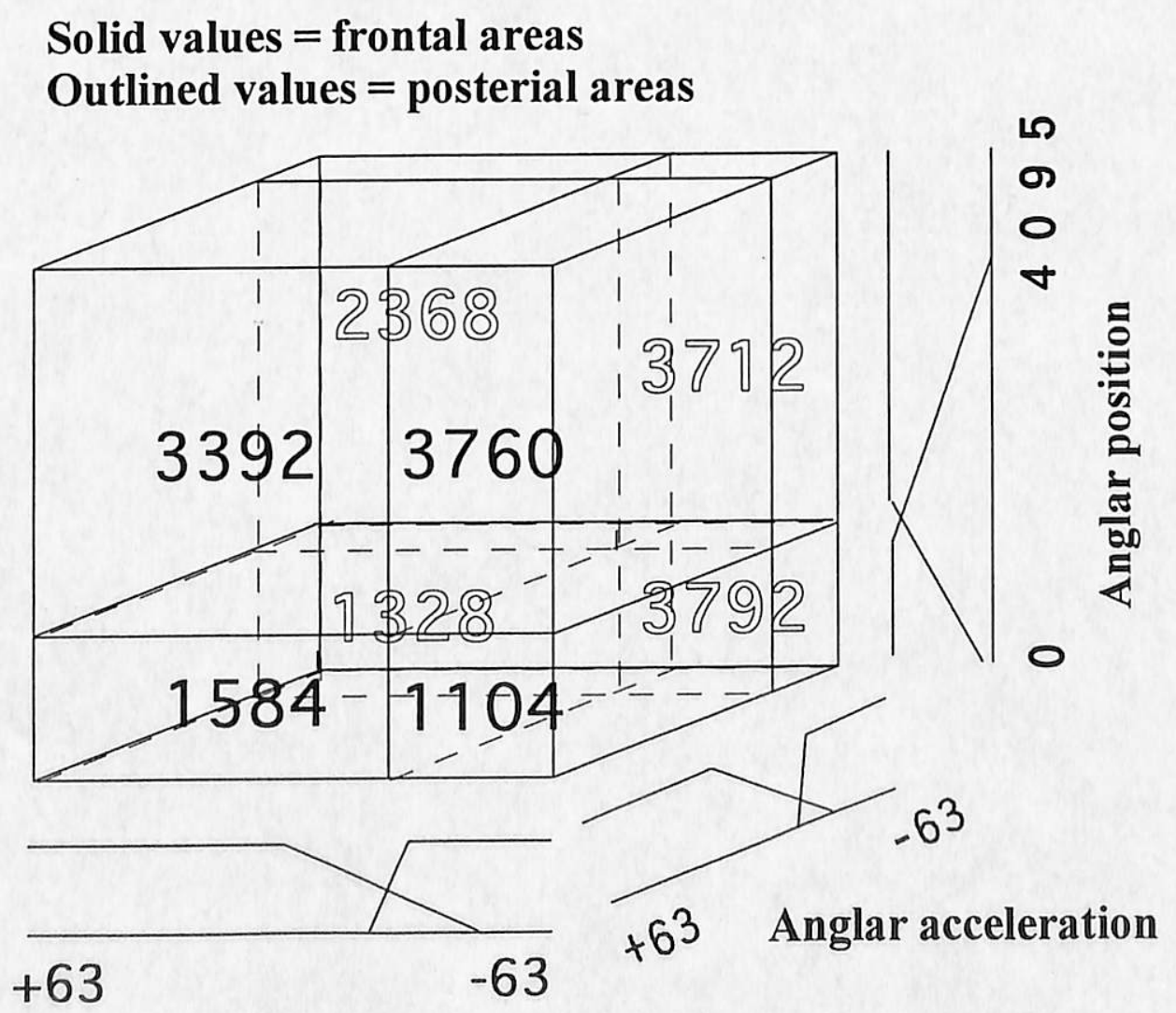

Anglar speed

Fig. 3. Example of fuzzy rule 
Some examples of the interpreted fuzzy rules are:

(1) IF the virtual opponent is superior in angle, THEN his force is big regardless its angular velocity and angular acceleration.

(2)IF the virtual opponent is pushed back (angular acceleration $<0$ ),

THEN his force is big to make a counterattack.

(3)Generally speaking the force of the virtual opponent is weak when he is inferior in angle. However, IF he is pushed back in the inferior situation, THEN his force becomes big not to be defeated.

\section{CONCLUSION}

Based on the creation of a virtual armwrestling opponent, we obtained classifier rules and translated them into a small number of fuzzy rules enabling ease of use. Finally, we evaluated the obtained fuzzy rules and compared them with the current knowledge base. In order to win, the rules that resulted in the virtual opponent winning were kept and used as the next initial settings, this modification enhanced the sense of virtual reality. This kind of optimization technique is used intuitively by humans and is thus essential to give a sense of humanness to a virtual counterpart. This interactive GA aspect may be considered another useful tool in the enhancement of the sense of virtual reality [6][7].

\section{REFERENCES}

[1] T. Takeda, Y. Tsutsui, "On the Computer Simulation of Ball Dribble in the Virtual Environment", HCI International '95 in Tokyo, July. 1995, pp. 473-478

[2] T. Takeda, Y.Tsutsui, "Development of a Virtual Training Environment", ASME Winter Annual Meeting, Vol. DSC-49, Dec. 1993, pp.
$1-10$.

[3] T. Takeda, S. Kamohara,"Construction of VR system to the arm wrestling with virtual person,", Trans. of the Inst. of Electr., Inform. and Commun.Eng. Vol.J79-A, No.2, (1996), pp.489-497.(in Japanese)

[4] T. Takeda, T.Kaneko, "Construction of a VR System for Arm Wrestling with a Virtual Person", International Conference on Virtual Systems and Multimedia VSMM'96 in Gifu, 1996, pp. 417-422.

[5] Lee, M. A. and Takagi, H., "Integrating Design Stage of Fuzzy System using Genetic Algorithms," IEEE 2nd Int'l Conf. on Fuzzy Systems (FUZZ--IEEE'93), Vol. 1, San Francisco, CA USA , March, 1993, pp.612617.

[6] H. Takagi, "System Optimization Without Numerical Target,"1996 Biennial Conference of the North American FuzzyInformation Processing Society (NAFIPS'96), Berkeley, CA, USA, June, 1996 pp.351-354.

[7] H. Takagi,, "Interactive GA for System Optimization: Problems and Solution," 4th European Congress on Intelligent Techniques and Soft Computing (EUFIT'96), Aachen, Germany, Sept., 1996, pp.1440-1444. 